Ministry of Education Iraqi Directorate of Education Baghdad Karkh III

First Conference Department of Preparation and Training Division of Research and Studies وزارة التربية العراقية ملديرية تربية بغلاد الكرخ الثالثة الهؤتمر الاول قسم الاعداد والتلدريب ثعبة البحوث والدراسات

\title{
Decision making Relation to Emotions management at Headmasters of Secondary and Preparatory Schools
}

\author{
Noora Hazim Jawad \\ Directorate of Baghdad Education Karkh III, Ministry of Education, Baghdad, Iraq \\ noorahazim86@gmail.com
}

\begin{abstract}
The research aimed to measure decision-making, measure emotion management, know the nature of the relationship between decision-making and emotion management of the principals of middle and Secondary Schools. To achieve the objectives of the research, two tools were used, namely the decision-making scale and the emotional management scale adopted by the researcher. The other measure of emotion management consists of (42) paragraphs, the current research sample consisted of (111) managers and managers of the third Karkh education. The results showed that managers have a high level of decision-making ability, that managers have a high ability to manage emotions.
\end{abstract}

Keywords: Decision making, Emotions management, Psychology, Secondary Study, Preparatory Study.

\section{اتخاذ القرار وعلاقته بإدارة الانفعالات لدى مدراء المدارس المتوسطة}

\author{
والاعدادية \\ نورا حازم جواد \\ وزارة التربية، مديرية تربية بغداد الكرخ الثالثة، بغداد، العراق \\ noorahazim86@gmail.com
}

المستخلص استهدف البحث قياس اتخاذ القرار، قياس ادارة الانفعالات، تعرف طبيعة العلاقة بين اتخاذ القرار وإدارة الانفعالات لدى هدراء المدارس المتوسطة والاعدادية. لتحقيق أهداف البحث تم استخدام أداتين هما مقياس اتخاذ القرار ومقياس ادارة الانفعالات الذي تبنتهما الباحثة وتم التأكد من صدق وثبات المقياسان، وأصبح المقياس بصورته النهائية يتكون من (27) فقرة. أما المقياس الاخر الخاص بإدارة الانفعالات يتكون من (42) فقرة، تكونت عينة البحث الحالي من (111) مديراً وهديرة من تربية الكرخ الثالثة. وقد أظهرت نتائج البحث ان المدراء لديهمم مستوى عالي من القدرة على اتخاذ القرار، ان المدراء يتمتعون بالقدرة العالية على ادارة الانفعالات، واظهرت النتائج وجود علاقة موجبة دالة احصائيا بين اتخاذ القرار وادارة الانفعالات وتم تقديم عدة توصيات ومقترحات. الكلمات الدالة: اتخاذ القرار، إدارة الانفعالات، علم النفس، المرحلة المتوسطة، والمرحلة الإعدادية.

Jawad, N. (2019). Decision making Relation to Emotions management at Headmasters of Secondary and Preparatory Schools. Journal Port Science Research, 2(3), 567-592. doi.org/10.36371/port.2018.02.3.12. 
إن اتخاذ القرار عملية مهمة لأنها تمس الحاضر وتغير الواقع وتمتد بأثارها الى المستقبل وهي تحتاج الى دراسة متأنية تستند الى قاعدة واسعة من المعلومات الدقيقة فيما يتعلق بموضوع القرار الذي يراد التوصل اليه [1]. تعد عملية صنع القرارات من المهام الجوهرية للمدير بوصفه الضابط لعمليات صنع القرارات، والمحلل الموضوعي للبدائل الموجودة والمفاضلة بينها للوصول للقرار الملائم لحاجة المدرسة وإمكانياتها، وإن مدير الهدرسة يواجه العديد من المشكلات اثناء أدائه لمهامه الروتينية والتي تتطلب عمليات معقدة من التفكير لاتخاذ قرارات متنوعة [2]. وقد يتردد وتشل قدرته على

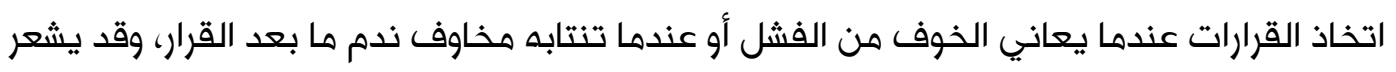
بالقلق عند اتخاذه قرارا معينا لحل مشكلة ما لأن قراره قد لا يحظى بهوافقة جميع الأفراد المعنيين، ويؤكد ميلرز وآخرون (Mellers et al,1998) أن للانفعالات تأثيرات قوية على القرارات التي يتخذها الفرد، وأن نتائج هذه القرارات لها تأثيراتها القوية على الانفعالات [3]. ولهذا يجب أن تتوفر في مدير

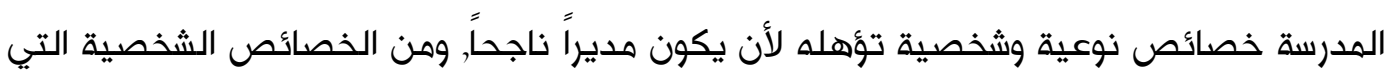
يجب على مدير المدرسة التمتع بها هي قدرته على إدارة انفعالاته والسيطرة عليها في مختلف المواقف التي يمر بها, ذلك إن المدير الناجح هو الذي يكون متوازناً نفسياً وانفعالياً، ويمتلك المعرفة بكيفية التعامل مع انفعالاته المختلفة والقدرة على اظهار الانفعال المناسب للمواقف المختلفة من حيث نوع الانفعال (سعادة، حزن) والدرجة (معتدل، متطرف)، فالذي لديه القدرة على ادارة انفعالاته يظهر ذلك في مدى ادارته وتحكمه بانفعالاته الإيجابية والسلبية بما يحقق توازنه النفسي [4]. ومن خلال عمل الباحثة في الميدان التعليمي فقد تحسست مشكلة بحثها فقد تبلورت هذه المشكلة التي يمكن صياغتها بالسؤال الآتي:

\section{ما علاقة اتخاذ القرار بإدارة الانفعالات لدى مدراء المدارس المتوسطة والاعدادية؟}

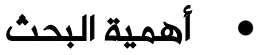

يعد موضوع صنع القرار واتخاذه من الموضوعات ذات الأهمية الكبرى وإن نظرة لواقع حياتنا تبين إن معظم أوقاتنا سواء كنا أفراداً أو جماعات بحاجة الى صنع واتخاذ قرار ما، فكل ناحية من نواحي حياتنا تحكمها القرارات سواء كنا أعضاء في أسرة أو مدرسة أو في مجال العمل كمدراء أو معلمين, ويعد من أهم العناصر وأكثرها أثرا في حياة المؤسسات الادارية, فهو جوهر عمل القيادة الادارية, وأصبح نجاح المدير في عمله يتوقف إلى حد كبير على مدى ما تحرزه القرارات التي يتخذها من نجاح, وتعد عملية

اتخاذ القرارات مهمة نتيجة للتغيرات الكثيرة في العملية التعليمية والتي أصبح على هديري المدارس الإلهام بها [5]. أشار " كنعان 2007 " إلى ان عملية اتخاذ القرار هي مجموعة من خطوات

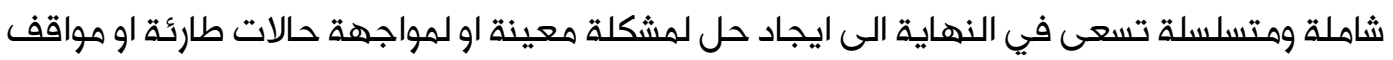


معينة مختلفة الموضوع او لتحقيق اهداف مرسوهة وقد تكون المشكلات القائمة واضحة ومعروفة الابعاد والجوانب او قد تكون غامضة بالنسبة لأبعادها وللأسباب الهكونة لها فالقرارات ماهي الا سلسلة متصلة بعضها ببعض وكل قرار كبير يتبعه سلسلة متصلة من القرارات الى الحد الذي تكون فيه القرارات صغيرة جدا، فكل قرار يسبقه قرار ويتبعه قرار الى ان يتم تنفيذ وتحقيق الأهداف الموضوعة والمحددة [6]. ويتطلب ذلك أن يكون مدير المدرسة ذا شخصية قيادية تربوية، تأهله لصناعة القرارات وان يكون لديه القدرة على تحديد المشكلة تحديدا دقيقا والتمييز بين المشكلات الأساسية والثانوية، والإلمام الكافي بجميع الحلول المهكنة للمشكلة والقدرة على التنبؤ بجميع النتائج المتوقعة لجميع الحول المهكنة [7].

ويؤكد كولمان (Coleman) بان ادارة الانفعالات هي اساس الوعي الاجتماعي والتواصل مع الاخرين واساس النجاح في الحياة، فهي تؤدي دورا كبيرا في تحديد نوعية حياة الفرد وتتحكم بسلوكه وهدى توافقه مع نفسه وهع بيأته الاجتماعية [8]. وعليه ان يتسم مدير المدرسة بخصائص وصفات حيوية، مثل القدرة على التعامل مع الطلبة وأن يكون موضوعياً في معالجة المشكلات المدرسية فضلا عن اتسامه بالضبط الانفعالي والقدرة على ان يكون متوازناً انفعالياً ومسيطراً على انفعالاته سواء كانت ايجابية ام سلبية في مواجهة المواقف والمشكلات المختلفة واوضحت بتاستيني" (Batastini,2001) القيادة في المواقف المختلفة، وكذلك يتميزون بالقدرة على الابتكار والقدرات الإبداعية [9].

\section{وفي ضوء ما تقدم يمكن إبراز أهمية هذه الدراسة في النقاط الآتية} تساعد المسؤولين في وزارة التربية والتعليم في معرفة الوسائل التي تحسن من عملية اتخاذ القرار

$$
\text { على المستوى التنفيذي في المدرسة، كمساهمة في إثراء البحث العلمي. }
$$

تأتي أهمية دراسة ادارة الانفعالات لدى مدراء المدارس المتوسطة والاعدادية ذلك لأن دور مدير المدرسة يفرض عليه ان يكون قادراً على الامساك بزمام الأمور وعلى ضبط نفسه وانفعالاته وحفظ توازنه ومواجهة المواقف المختلفة بثبات وأن تكون لديه القدرة على ادارة انفعالاته والسيطرة

عليها. يمكن الإفادة من نتائج الدراسة في تطوير أداء مدراء المدارس، من خلال النتائج والتوصيات

$$
\text { والمقترحات التي توصي بها. }
$$

$$
\text { يهدف البحث الحالي الى: الهداف البحث: }
$$

1) قياس اتخاذ القرار لدى مدراء المدارس المتوسطة والاعدادية.

Jawad, N. (2019). Decision making Relation to Emotions management at Headmasters of Secondary and Preparatory Schools. Journal Port Science Research, 2(3), 567-592. doi.org/10.36371/port.2018.02.3.12. 
2) قياس ادارة الانفعالات لدى مدراء المدارس المتوسطة والاعدادية.

3) 3-الفروق في اتخاذ القرار تبعا لمتغير الجنس (ذكور- اناث) والمرحلة (متوسطة - إعدادية).

4) الفروق في إدارة الانفعالات تبعا لمتغير الجنس (ذكور- اناث) والمرحلة (متوسطة-إعدادية).

5) تعرف طبيعة العلاقة بين اتخاذ القرار وإدارة الانفعالات لدى مدراء المدارس المتوسطة

$$
\text { والاعدادية. }
$$

$$
\text { حدود البحث }
$$

يتحدد البحث الحالي بهدراء المدارس المتوسطة والاعدادية في محافظة بغداد مديرية التربية الكرخ (الثالثة) ومن كلا الجنسين (ذكور- اناث) للعام الدراسي (2018- 2019).

\section{• • تصديد الهصطلحات}

اولاً اتخاذ القرار Decision Making

تعريف (جينس ومان jains\& mann1977) "هو عملية اختيار الفرد لطريقة فعل بين اثنين أو أكثر من البدائل أثناء تحقيقه لأهدافه ويتضمن خمسة أبعاد هي: الثقة بالنفس كمان والاحتراس Vigilance والتوتر Panic والتجنب Evasiveness واللامبالاة Complacency" [10].

$$
\text { تبنت الباحثة تعريف جينس ومان تعريفا نظريا. }
$$

التعريف الإجرائي لمفهوم اتخاذ القرار فهو الدرجة الكلية التي يحصل عليها المستجيب عند إجابته

$$
\text { عن فقرات مقياس اتخاذ القرار لجينس ومان. }
$$

\section{ثانياً ادارة الانفعالات (Management of Emotions)}

ماير وسالوفي (Mayer \& Salovey,2001) القدرة على فهم المشاعر والانفعالات الذاتية، الانفتاح بالمشاعر نحو الآخرين ومشاركتهم بهذه المشاعر مما يؤدي الى التوازن الانفعالي [11]. تبنت الباحثة تعريف ماير وسالوفي (Mayer \& Salovey,2001) تعريفا نظريا كونها تبنت نظريتهما لهذا البحث.

التعريف الاجرائي هو الدرجة الكلية التي يحصل عليها المستجيب من خلال اجابته على فقرات مقياس إدارة الانفعالات المستخدم في البحث الحالي.

أولا اتخاذ القرار Decision-making 
لقد حظيت عملية اتخاذ القرار باهتمام من علماء الادارة وعلم النفس، لكونها تلازم الانسان في حياته اليوهية والوظيفية وتلبي احتياجاته وتحقق له التكيف ويعد اتخاذ القرار من أهم العناصر وأكثرها أثرا في حياة الفرد، كما انه يعد من أهم الوظائف الاساسية والجوهرية للقائد الاداري ولذلك يوصف القادة الذين يتخذون قرارات بأنهم العامل الاول والاساس في هذه الإدارة [12]. والقرار الذي يتخذه الفرد في موقف معين يحدد المسار الذي سيسلكه، أو مجموعة الاستجابات والاجراءات الذي سينفذها للوصول إلى الهدف أو حل مشكلة تواجهه، ومعظم تصرفات الفرد هي نتاج تلقائي للقرارات التي يتخذونها، فعند مواجهته لموقف ما فإنه يقوم بعملية تحكيم عقلي يتوصل من خلالها إلى اختيار أنسب السلوكيات والاجراءات التي تقود إلى اثار إيجابية أو تجنبه العواقب السلبية غير المرغوبة أو كلاهما معا [13]. وان اتخاذ القرار وظيفة أساسية ومهمة من وظائف الإدارة، لان نجاح أي عملية إدارية يرتبط بصنع واتخاذ القرارات [14]. من النظريات التي فسرت اتخاذ القرار هي:

النظرية التقليدية للقرار(الكلاسيكية) تسمى أيضا بالنظرية المثالية، تفترض هذه النظرية إن متخذ القرار كامل الرشد ويسعى لاتخاذ قرارات رشيدة، فضلا عن تعظيم الربح أو العائد، وادخل على هذه النظرية العديد من التعديلات لجعلها أكثر قدرة على التطبيق، ويطلق على هذه النظرية بالمدرسة العلمية لاعتمادها على قواعد علمية ثابتة في معالجة المشكلات الادارية وحلها بالأسلوب العلمي

نظرية القرار غير الرشيد (نظرية سايهون) ان من أبرز دعاة هذه النظرية سايمون (simon) الذي انتقد

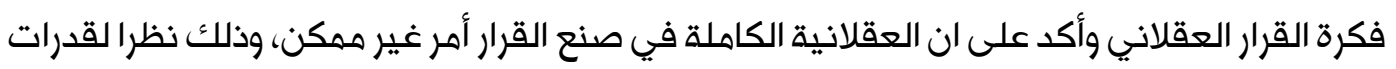
الانسان المحدودة ولما يتعرض له من ضغوط بيئية وبالتالي، ان على متخذ القرار أن يسعى الى حلول مرضية لا مثالية بحيث تتلاءم مع الضغوط البئية والاحتياجات الشخصية والتي تحقق لهى مستوى

$$
\text { مقبول من الرضى والاشباع [16]. }
$$

نظرية جينس ومان Janis \& Mann Theory تفترض هذه النظرية بأن عملية اتخاذ القرار يسبب

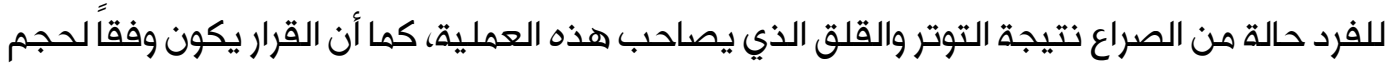
الصراع الذي يمرَّ به الفرد سواء كان يمثل حالة دافعية أو انفعالية والتي تسبب الشعور بالضغط والتوتر, وأكد جينس ومان Janis and Mann إن حالة التوتر الناشئ عن حالة الصراع الهصاحبة لعملية اتخاذ اقرار هي التي تحدد الاسلوب الذي يتخذه الفرد في اختيار بديل من البدائل الصحيحة و كيفية

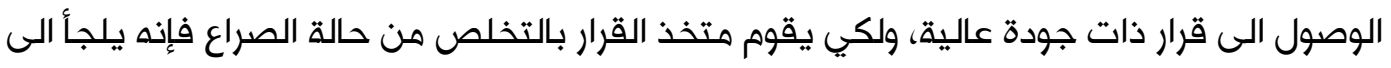
القيام بجمع المزيد من المعلومات حول هذه البدائل وإجراء سلسلة منظمة وفاعلة من عمليات التقييم 
لكل بديل على حدة وإعادة تقييمه في ضوء ما يحمله الفرد من افكار وآراء ومعتقدات واتجاهات [17]. وقد أشارت نظرية الصراع ومن خلال الدراسات التي أجريت على الأفراد الذين يتميزون بالثقة بالنفس في اتخاذ قراراتهم الناجحة الى أن عملية اتخاذ قرار ثابت ومستقر تتطلب من الفرد متخذ القرار المـرور بعدة مراحـل وهـذه المراحل هـي: (مرحلة تقدير التحدي، مرحلة تقييم البدائل، وزن البديل، التفكير مليا بالقرار، الالتزام بالقرار) [18]. وتشمل هذه النظرية خمسة أبعاد رئيسة هي الثقة بالنفس هرل Sigilance والتوتر Sanic والاحتراس و والتجنب Evasiveness confidence Janis \& Mann هذه الأبعاد في محورين أساسيين هما النمط Complacency وقد صنف جينيز ومانر التوافقي لاتخاذ القرار، والنمط غير التوافقي، ويشير النمط التوافقي إلى السلوك المتروي المدروس بعناية والقائم على التريث والثقة بالنفس، بينما يشير النمط غير التوافقي إلى التوتر والتجنب التب التبان واللامبالاة عند اتخاذ القرارات. تبنت الباحثة نظرية جينس ومان لأنها أعطت أهمية كبيرة في تفسير عملية اتخاذ القرار.

\section{ثانيا ادارة الانفعالات: Emotions management}

ان مفهوم إدارة الانفعالات مفهوم حديث، ويوجد خلاف حول كونه قدرات عقلية أو مهارات اجتماعية أو لسمات شخصية، والفرد الذي لديه القدرة على ادارة انفعالاته يتمكن من الاحتفاظ بالمرونة اللازمة لإدارة مختلف المواقف الصعبة وتمكنه بالتالي من التوصل الى خيارات سلوكية سليمة تحظى بالقبول من قبل الجميع. [19] ، وبدراستها نجد أنها انشقت على نفسها إلى اتجاهين: الاتجاه الأول عدها قدرة معرفية وأشار الى أنها "القدرة على فهم المشاعر والانفعالات الذاتية والانفتاح بالمشاعر نحو الآخرين والتحكم فيها وتنظيمها ويعرف ماير وسالوفى إدارة الانفعالات بأنها القدرة على فهم المشاعر والانفعالات الذاتية والانفتاح بالمشاعر نحو الآخرين ومشاركتهم بهذه المشاعر مما يؤدي الى التوازن الانفعالي.

الاتجاه الثاني عدها قدرات معرفية وسمات أو مهارات شخصية ويمثله جولمان وبار- أون، وأشارا بأنها أساس الوعي الاجتماعي والتواصل مع الآخرين وأساس النجاح في حياة الأفراد، فهي كفاءات ومهارات قابلة للتطوير وضرورية لتكامل فريق العمل [20]. وتعد أدارة الانفعالات مفتاح النجاح في الحياة المهنية مقارنة بالذكاء الأكاديمي الذي هو مفتاح النجاح في الحياة الدراسية [21] . وهذا ما اكدته دراسة جيري (Geery,1997) الى ان مديري المدارس الذين يتمتعون بإدارة انفعالات عالية يتميزون باستخدام المعرفة للحفاظ على الهدوء, والتحكم في الانفعالات والتفاؤل وحل المشكلات وفهم انفعالات الاخرين وبناء (وابط الثقة مع الاخرين [22], وان الاناث ذوات ادارة الانفعالات المرتفعة يتسمن بالتعبير عن مشاعرهن بصورة مباشرة، ويثقن في قدراتهن، والحياة بالنسبة لهن معنى، بالإضافة الى انهن 
مثل الرجال، اجتماعيات غير متحفظات، كما انهن يستطعن التكيف مع الضغوط النفية، ومن السهل عليهن تكوين علاقات اجتماعية جيدة [23]. من النظريات التي فسرت معنى ادارة الانفعالات هي: نظرية بار_اون Bar-ons 1998 لإدارة الانفعالات قام بار أون بتوسيع معنى ادارة الانفعالات من خلال

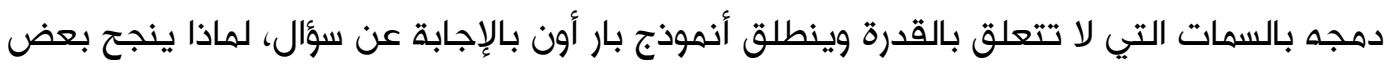
الناس في الحياة أكثر من غيرهم؟ وحددها في خمس مجالات، هي الوظائف الشخصية، والمهارات الشخصية، والتكيفية، وادارة الضغوط، والمزاج العام [24].

نظرية ماير وسالوفي Mayer \& Salovey وتنص النظرية على ان الانفعالات تحوي معلومات تتعلق بالعلاقات الداخلية لمنظومة الفرد النفسية والعلاقات الخارجية المتعلقة بالأشخاص والمثيرات الخارجية، وحينما تتغير علاقة الشخص مع شخص اخر أو مع شيء ما فأن انفعالاتهم مع بعضهم بعضا أو نحو الشيء تتغير ايضا ويتم الاحساس بالخوف من الشخص الذي يعتبر مهددا للغير، أما الشخص الذي لا يتوقع منه اضرارا تهديد فهناك على الاقل ميل تجاهه، وتصحب هذه العلاقات سواء أكان حقيقة أو متخيلة اشارات وتعبيرات تطرأ عليها وهي الانفعالات [25]. واكد مايرز (Mayer's) ان ضبط الانفعال وتقيمه يتمثل في القدرة على تحديد الانفعال في الحالات الجسمية للفرد كذلك تحديد الانفعالات لدى الاخرين من خلال العمل ومهارات الفرد وسلوكه وهظهره، كذلك تساعد على حل المشكلات وفهم المشاعر المعقدة وخليط المشاعر مثل الرهبة والخـوف المفاجئ [26]. وقد حدد ماير وسالوفي أربع مكونات او قدرات رئيسية منفصلة لكنها متجانسة مع بعضها تعكس مراحل النمو الانفعالي وهذه المكونات (القدرات) هي: Emotional Perception مكون الإدراك الانفعالي وههاراته (قدرة إدراك الانفعالات) 1) وهو قدرة الفرد على معرفة الحالة الانفعالية الوجدانية من خلال الحالة الفيزيقية ومشاعر

$$
\begin{aligned}
& \text { وافكار الفرد والقدرة على التعبير عن الانفعالات [27]. } \\
& \text { 2) مكون التيسير الانفعالي وههاراته (قدرة توظيف الانفعالات) }
\end{aligned}
$$

يدور هذا المستوى حول تأثير الانفعال في الذكاء فهو يصف الكيفية التي يؤثر بها الانفعال على المعرفة مثل حل المشكلات واتخاذ القرارات، أي انه يصف الاحداث الانفعالية التي تساهم 
3) مكون الفهم الانفعالي وههاراته (قدرة فهم الانفعالات) Emotional Understanding يختص هذا المستوى بالمعارف أكثر من النظام الانفعالي كما يختص بمدى قدرة الفرد على

$$
\text { تطبيق تلك المعارف في الواقع اليومي [28]. }
$$

4) إدارة الانفعالات (Management Emotions) وهو المستوى الاعلى ويشتمل على تنظيم الانفعالات في ذات الفرد ولدى الاخرين ويرى كل من ماير وسالوفي ان احدى مقدمات الذكاء الانفعالي هو ان الاستجابات الانفعالية قد تتسق او لا تتسق مع المعتقدات الخاصـة عن الانفعـالات. وتشير الى قدرة الفرد على التحكم في الانفعالات السلبية وكسب الوقت للتحكم فيها وتحويلها الى انفعالات ايجابية، وعلى إدارة أفعاله وأفكاره ومشاعره بطريقة متوافقة ومرنة عبر مواقف وبيئات اجتماعية مختلفة، وكل فرد له نمطان من المشاعر والانفعالات سارة ومبهجة(إيجابية) ومشاعر وانفعالات مكدرة وحزينة(سلبية)، وينبغي اظهارها كل في موقفها الهناسب، لأن تنوع الخبرات بين الفرح والحزن، يعطي للحياة تجدداً وحيوية، إن الحياة التي تتسم بالسواء هي التي تتسم بالتوازن [29]. وتشمل ادارة الانفعالات على اربعه مكونات هي: A . الانفتاح في المشاعر السارة وغير السارة. B المشاركة في الانفعالات مع الاخرين.

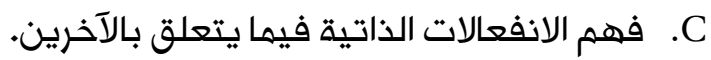

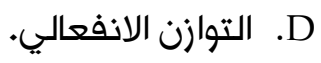
تبنت الباحثة نظرية ماير وسالوفي لأنها كانت أقرب في تفسير معنى ادارة الانفعالات.

\section{الدراسات التي تناولت اتخاذ القرار}

دراسة الأسدي (2013) "انماط الشخصية لمديري المدارس الاعدادية في ضوء نظرية يونغ وعلاقتها باتخاذ القرار" بلغ حجم عينة الدراسة 200 مدير ومديرة موزعين على المديريات الستة العامة لتربية مدينة بغداد وانتهت الدراسة بالنتائج الاتية: 1) يتميز افراد العينة بمستوى عال لنمط الشخصية الانبساطية 2) يتميز افراد العينة بمستوى عال باتخاذ القرار

3) وجود علاقة طردية معنوية بين نمط الشخصية (الانبساطية) واتخاذ القرار 4) لا توجد فروق ذات دلالة احصائية في متوسطات درجات افراد العينة لنهط الشخصية

$$
\text { القرار تبعا لمتغير الجنس ذكور، اناث. }
$$


دراسة ماكالبو (Maccalupo,2009) "دور ادارة الانفعالات في القيادة المتميزة" استهدفت هذه الدراسة الى تعرف العلاقة الارتباطية بين القيادة وكل من الاتزان الانفعالي، وقوة الاستراتيجية،

$$
\text { والقيادة الموقفية، واظهرت النتائج الى }
$$

1) وجود علاقة ارتباطية بين الاتزان الانفعالي واتخاذ القرار لدى قادة المدارس.

2) وجود علاقة ارتباطية دالة احصائيا بين الاتزان الانفعالي وقوة الاستراتيجيات والقيادة

$$
\text { الموقفية ودلت النتائج بان الاتزان الانفعالي مكتسب ويمكن تعلمه. }
$$

\section{2. المنهجية والإجراءات}

أولاً مجتمع البحث Population of Research يتألف مجتمع البحث من مدراء المدارس المتوسطة والاعدادية في محافظة بغداد/ المديرية العامة لتربية الكرخ (الثالثة) والبالغ عددهم (111) مديراً ومديرة مدرسة بواقع (70) مديراً و(41) مديرة والجدول (1) يوضح ذلك

جدول رقم (1) مجتمع البحث من مدراء المدارس المتوسطة والاعد/دية

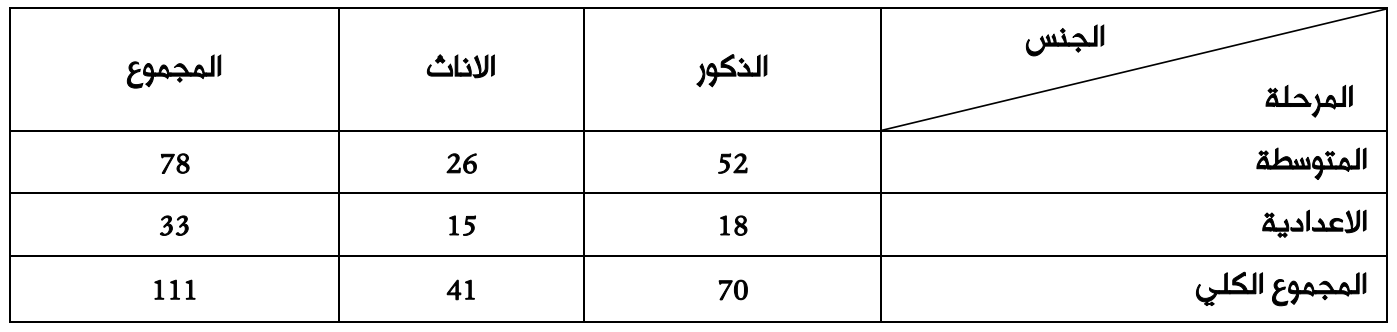

ثانيا عينة البحث نظراً لصغر حجم مجتمع البحث لجأت الباحثة الى اعتماد الحصر الشامل لكل افراد مجتمع البحث والتطبيق على افراد مجتمع البحث جميعهم والبالغ عددهم (111) مديرا وهديرة، وكما موضح في الجدول (1). ثالثا أداتا البحث لغرض تحقيق أهداف البحث، فقد تطلّبَ وجود مقياس اتخاذ القرار وادارة الانفعالات وبعد الاطلاع على الأدبيات والدراسات تبنت الباحثة المقاييس للمتغيرين استناداً الى النظريات التي

$$
\text { تبنتها الباحثة لكل متغيّر من متغيرات البحث وكالاتي: }
$$

1 1 ) مقياس اساليب اتخاذ القرار Styles Decision Making

Jawad, N. (2019). Decision making Relation to Emotions management at Headmasters of Secondary and Preparatory Schools. Journal Port Science Research, 2(3), 567-592. doi.org/10.36371/port.2018.02.3.12. 
من أجل تحقيق هذا البحث قامت الباحثة بتبني مقياس مهودر(2014)المبني على وفق نظرية جيمس ومانن. Janis \&mann وصف المقياس

A ت تبلغ عدد فقرات المقياس (30) فقرة ويجيب الفرد على مدرج خماسي أمام كل فقرة هي (تنطبق علي بدرجة كبيرة جدا، تنطبق علي بدرجة كبيرة، تنطبق علي بدرجة معتدلة،

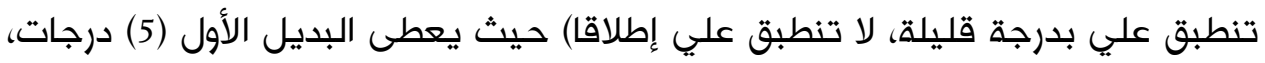
والبديل الثاني يعطى (4) درجات، والبديل الثالث يعطى (3) والبديل الرابع يعطى (2) والبديل الخامس يعطى (1) هذا بالنسبة للفقرات الايجابية أما فيما يتعلق بالفقرات السلبية تعطى الدرجات (1), (2), (3).(4),(5)، وكانت اعلى درجة المقياس(150) واقل درجة على المقياس(30) والوسط الفرض(90) درجة. B القوة التميزية لفقرات مقياس اتخاذ القرار بعد تطبيق المقياس على عينة التحليل الاحصائي ولغرض الإبقاء على الفقرات المميزة، t-) اجري تحليل الفقرات باستخدام أسلوب المجموعتين المتطرفتين وطبق الاختبار التائي لعينتين مستقلتين لاختبار دلالة الفروق بين المجموعتين العليا والدنيا على كل فقرة، (test وقد عدت القيمة التائية مؤشراً لتمييز كل فقرة من خلال مقارنتها بالقيمة الجدولية البالغة (2) عند مستوى دلالة (0.05) وبدرجة حرية (52) وعلى ضوء ذلك تم حذف (3) فقرات تأخذ التسلسلات (17,6, 24). وبذلك أصبح المقياس بصورته النهائية يتألف من (27) فقرة. C C. علاقة درجة الفقرة بالدرجة الكلية ان صدق الفقرة يعدّ دليلا على صدق المقياس ويرى كرول (Kroll,1966) أن حساب ارتباط درجة الفقرة بالدرجة الكلية للمقياس أكثر دقة من صدقها الظاهري، لأنه يكشف عن قياس الفقرة للمفهوم نفسه الذي تقيسه الدرجة الكلية [30]. ولحساب الارتباطات تم استخدام معامل ارتباط بيرسون، وقد اختبرت دلالة معاملات الارتباط عن طريق مقارنتها مع القيمة الجدولية لدلالة معاملات الارتباط، عند مستوى دلالة (0,05) وبدرجة حرية (99) والبالغة (0,196) وقد تم حذف (3) فقرات تأخذ التسلسلات (6، 23، 24) لكونها حصلت على معاملات ارتباط غير دالة.

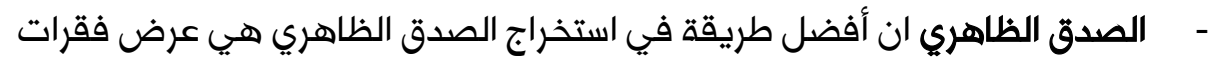
المقياس على مجموعة من المحكمين للحكم على صلاحيتها في قياس الخاصية 
المراد قياسها [31]، وقد تم التحقق من الصدق الظاهري للمقياس من خلال عرض فقرات وبدائل الاجابة وتعليماته على مجموعة من المحكمين المختصين في التربية وعلم النفس وقد قاموا بفحصها وتقدير صلاحيتها في قياس ما أعدت لقياسه، وقد حصلت فقرات المقياس جمعيها على نسبة اتفاق (100\%) من المحكمين. صدق البناء وقد تم التحقق من صدق البناء من خلال علاقة الفقرة بالدرجة الكلية

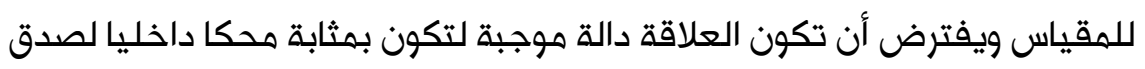
البناء وقد حسبت معاملات الارتباط بين درجة كل فقرة والدرجة الكلية للمقياس، وقد كانت جمعيها دالة احصائيا عند مستوى دلالة (0.05) ماعدا الفقرات (6, 23,

ثانيا الثبات Reliability يعرف الثبات بأنه اتساق في نتائج المقياس [32]، وكلما كان المقياس أكثر ثباتاً أصبح أكثر موثوقية [33]. تم التحقق من ثبات المقياس بطريقة التجزئة النصفية وباستخدام معادلة ألفا كرونباخ كالاتي: طريقة التجزئة النصفية Split Method) Half تقوم فكرة معامل الثبات بطريقة التجزئة النصفية على تقسيم فقرات المقياس بعد الإجابة عنها الى قسمين (زوجي وفردي) تمثل فيه أرقام الفقرات الفردية القسم الاول في حين تمثل أرقام الفقرات الزوجية القسم الثاني، ثم يتم حساب معامل الارتباط بين درجات القسمين والذي يمثل معامل الثبات [34]. وقد اعتمدت الباحثة ذلك في استخراج ثبات المقياس اذ بلغ معامل الثبات (0,70) وبعد تصحيحه بمعادلة سبيرمان -براون بلغ (0,71) وهو معامل ثبات جيد. معادلة ألفا كرونباخ Alfa Cronbch تعد هذه الطريقة مفضلة لقياس الثبات فهي تقيس الاتساق الداخلي والتجانس بين فقرات المقياس [35] أي أن الفقرات جمعيها تقيس فعلا الخاصية نفسها وهذا يتحقق عندما تكون الفقرات مترابطة مع بعضها البعض داخل الاختبار كذلك ارتباط كل فقرة مع الاختبار كله، وتم تطبيق معادلة ألفا كرونباخ على درجات افراد عينة الثبات وقد بلغ معامل الثبات لمقياس اتخاذ القرار (0,88) وهو معامل ثبات جيد.

مقياس ادارة الانفعالات من أجل تحقيق هذا البحث قامت الباحثة بتبني مقياس (اللامي) المبني على وفق نظرية ماير وسالوفي. 
وصف المقياس يتكون المقياس من (48) فقرة، موزعة على (4) مجالات، امام كل منها خمسة بدائل هي (تنطبق علي دائماً - تنطبق علي غالباً - تنطبق علي احياناً - تنطبق علي نادراً - لا تنطبق علي ابداً)، عند التصحيح تأخذ الدرجات (1، 2، 3، 4، 5) للفقرات الإيجابية و (5، 4، 3، 2، 1) للفقرات السلبية.

القوة التمييزية لفقرات ادارة الانفعالات

بعد تطبيق المقياس على عينة التحليل الاحصائي ولغرض الإبقاء على الفقرات المميزة، اجري تحليل الفقرات باستخدام أسلوب المجموعتين المتطرفتين وطبق الاختبار التائي (t-test) لعينتين مستقلتين لاختبار دلالة الفروق بين الهجموعتين العليا والدنيا على كل فقرة، وقد عدت القيمة التائية مؤشراً لتمييز كل فقرة من خلال مقارنتها بالقيمة الجدولية البالغة (2) عند مستوى دلالة (0.05) وبدرجة حرية (52) وعلى ضوء ذلك تم حذف (6) فقرات تأخذ التسلسلات (6, 24, 36, 45, 47, 48). وبذلك أصبح المقياس بصورته النهائية يتكون يتألف من (42) فقرة.

\section{علاقة درجة الفقرة بالدرجة الكلية}

تم استخدام معامل ارتباط بيرسون، وقد اختبرت دلالة معاملات الارتباط عن طريق مقارنتها مع القيمة الجدولية لدلالة معاملات الارتباط، عند مستوى دلالة (0,05) وبدرجة حرية (99) والبالغة (0,196) وقد تم حذف (6) فقرات تأخذ التسلسلات (6, 24, 36, 47,48,45) لكونها حصلت على معاملات ارتباط غير دالة.

\section{الخصائص السيكومترية للمقياس}

اولا صدق المقياس وقد تم التحقق من الصدق من خلال المؤشرات الاتية

A الصدق الظاهري تم التحقق من الصدق الظاهري للمقياس من خلال عرض فقرات وبدائل الاجابة وتعليماته على مجموعة من المحكمين المختصين في التربية وعلم النفس وقد قاموا بفحصها وتقدير صلاحيتها في قياس ما أعدت لقياسه، وقد حصلت فقرات المقياس جمعيها على نسبة اتفاق (100\%) من المحكمين. B. صدق البناء: وقد تم التحقق من صدق البناء من خلال: - - ايجاد القوة التمييزية لفقرات المقياس. - ايجاد العلاقة الارتباطية بين درجة الفقرة والدرجة الكلية للمقياس. الثبات Reliability يعد مفهوم الثبات من المفاهيم الجوهرية في مجال القياس النفسي ويعني الاتساق في أداء الفرد والاستقرار في النتائج (Marint,1984:9). وتم التحقق من ثبات المقياس بطريقة التجزئة النصفية وباستخدام معادلة ألفا كرونباخ كالاتي: 
A طريقة التجزئة النصفية Split Method) Half تم استخراج ثبات المقياس اذ بلغ معامل

الثبات (0,76) وبعد تصحيحه بمعادلة سبيرمان -براون بلغ (0,87) وهو معامل ثبات جيد.

B. معادلة ألفا كرونباخ Alfa Cronbch تم تطبيق معادلة ألفا كرونباخ على درجات افراد عينة . B

الثبات وقد بلغ معامل الثبات لمقياس اتخاذ القرار (0,92). وهو معامل ثبات جيد يمكن

الركون اليه عند مقارنته مع المعيار المطلق. الوسائل الاحصائية: تم استخدام الوسائل

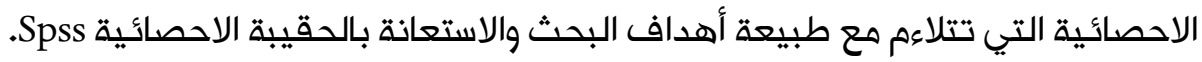

\section{3. الهنهجية والإجراءات}

التعرف الى اتخاذ القرار لدى مدراء المدراس المتوسطة والاعدادية أظهرت نتائج البحث أن المتوسط الحسابي لدرجات عينة البحث على مقياس اتخاذ القرار قد بلغ $(99,1188)$ درجة، وبانحراف معياري قدره $(1012,15)$ وعند مقارنة هذا المتوسط الحسابي بالمتوسط الفرضي للمقياس الذي يبلغ (78)

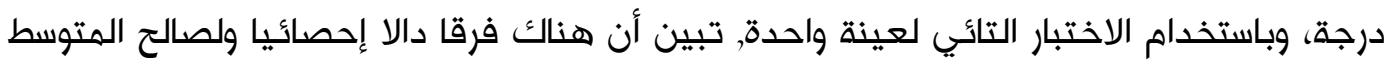
الحسابي للعينة، إذ بلغت القيمة التائية المحسوبة (055, 14)، وهي اكبر من القيمة التائية الجدولية البالغة (1,98) عند مستوى دلالة (0,05) وبدرجة حرية (100)، والجدول (2) يوضح ذلك.

\begin{tabular}{|c|c|c|c|c|c|c|c|}
\hline \multirow{2}{*}{ | مستوى الدلالة } & \multicolumn{2}{|c|}{ القيمة التائية } & \multirow{2}{*}{ الهتوسط الفرضي } & \multirow{2}{*}{ المعياري } & \multirow{2}{*}{ المتوسط الحسابي | } & \multirow{2}{*}{ 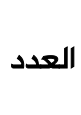 } & \multirow{2}{*}{ المتغير } \\
\hline & الجدولية & المحسوبة & & & & & \\
\hline دالة & 1.98 & 14,055 & 78 & 15,1012 & 99,1188 & 101 & تخاذ القرار \\
\hline
\end{tabular}

القيمة التائية الجدولية تساوي (1,98) عند مستوى (0,05) وبدرجة حرية (100). من خلال ما تقدم تبين ان متوسطات درجات مدراء المدارس المتوسطة والاعدادية على مقياس اتخاذ القرار اعلى من المتوسط الفرضي، ويمكن تفسير ذلك استنادا الى نظرية جينيزوهان 1977 (Janis \& mann الى أن المدراء لديهم مستوى عالي من القدرة على اتخاذ القرار يعود هذا الى ثقتهم بأنفسهم وقدرتهم على حل المشكلات وكذلك الاختيار الجيد لهدراء المدارس واعطاء النظام التعليمي لهم حرية اتخاذ القرار في

$$
\text { كثير من المواقف. }
$$

التعرف الى ادارة الانفعالات لدى مدراء المدارس المتوسطة والاعدادية. أظهرت نتائج البحث أن المتوسط الحسابي لدرجات عينة البحث على مقياس ادارة الانفعالات قد بلغ (4275, 154) درجة،

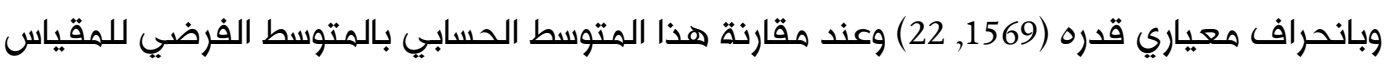
الذي يبلغ (123) درجة، وباستخدام الاختبار التائي لعينة واحدة، تبين أن هناك فرقا دالا إحصائيا 
ولصالح المتوسط الحسابي للعينة، إذ بلغت القيمة التائية المحسوبة (254, 14)، وهي أكبر من القيهة التائية الجدولية البالغة (1,98) عند مستوى دلالة (0,05) وبدرجة حرية (100)، والجدول (3) يوضح ذلك.

الجدول (3) دلالة الفرق بين المتوسط الحسابي والمتوسط الفرض والقيم التائية لأفراد العينة

\begin{tabular}{|c|c|c|c|c|c|c|c|}
\hline \multirow{2}{*}{ مستوى الدلالة } & \multicolumn{2}{|c|}{ القيمة التائية } & \multirow{2}{*}{ المتوسط الفرضي } & \multirow{2}{*}{ الانحراف المعياري } & \multirow{2}{*}{ المتوسط الحسابي } & \multirow{2}{*}{ | العدد | } & \multirow{2}{*}{ المتغير } \\
\hline & |الجدولية & |المحسوبة | & & & & & \\
\hline دالة ل & 1.98 & 14,254 & 123 & 22,1569 & 154,4275 & 101 & الانفعالات \\
\hline
\end{tabular}

القيمة التائية الجدولية تساوي (1,98) عند مستوى (0,05) وبدرجة حرية (100). من خلال ما تقدم تبين ان متوسطات درجات مدراء المدارس المتوسطة والاعدادية على مقياس اتخاذ القرار اعلى من المتوسط الفرضي ويمكن تفسير هذا استنادا الى نظرية ماير وسالوفي ان ادارة الانفعالات يمكن تعلمها وتطويرها بفعل النشاط العقلي والمعرفي والشخص الذي يتمتع بقدرة عالية على ادارة الانفعالات تكون له امكانية على الهشاركة والانفتاح على الاخرين وإدراكهم للواقع وتكيفهم مع احداث الحياة اليومية الضاغطة لتحقيق التوازن مع أنفسهم وهع الآخرين.

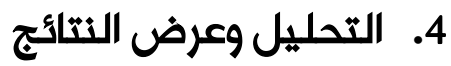

تعرف لفروق في اتخاذ القرار بحسب متغير الجنس (ذكور - اناث) والهرحلة (متوسطة - إعدادية). ولتحقيق هذا الهدف استخدمت الباحثة تحليل التباين الثنائي بتفاعل والجدول (4) يوضح ذلك. جدول (4) تحليل التباين الثنائي للكشف عن دلالة الفرق في/تخاذ القرار بحسب متغير الجنس ذكور واناث

\begin{tabular}{|c|c|c|c|c|c|}
\hline 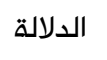 & القيمة الفائية المحسوبة & متوسط المربعات & درجة الحرية & مجموع المربعات & مصدر التباين \\
\hline دالة & 7,525 & 1457,158 & 1 & 1457,158 & المرحلة \\
\hline غير دالة & 0,266 & 51,418 & 1 & 51,418 & الجنس \\
\hline \multirow[t]{3}{*}{ دالة } & 15,426 & 2987,116 & 1 & 2987,116 & المرحلة + الجنس \\
\hline & & 193,644 & 97 & 18783,512 & الخطأ (المتبقي) \\
\hline & & & 100 & 22804,574 & الكلي \\
\hline
\end{tabular}

أظهرت النتائج بالنسبة لمتغير المرحلة وجود فروق دالة احصائيا اذ بلغت القيمة الفائية المحسوبة (7,525) وهي أعلى من القيمة الفائية والبالغة (3,92) وبالمقارنة بين المتوسطات تبين إن الوسط الحسابي لمدراء المرحلة الاعدادية والبالغ (1457,158) أعلى من الوسط الحسابي لمدراء المرحلة المتوسطة والبالغ $(51,418)$ مما يشير الى انه مدراء المدارس الاعدادية هم أكثر قدرة من مدراء المدارس المتوسطة في اتخاذ القرار واعتماد سلوك مؤثر وفعال بشكل ايجابي. اما بالنسبة لمتغير الجنس فقد جواد، نورا حازم. (2019). اتخاذ القرار وعلاقته بإدارة الانفعالات لدى مدراء المدارس المتوسطة والاعدادية. Journal Port doi.org/10.36371/port.2018.02.3.12.567-592 ، S(3) ، Science Research 
أظهرت النتائج عدم وجود فروق دالة احصائيا اذ بلغت القيمة الفائية المحسوبة (0,266) وهي أصغر من القيمة الفائية الجدولية عند مستوى دلالة (0,05) وبدرجتي حرية (1-97) والبالغة (3,92) أما بالنسبة للتفاعلات النهائية بين المرحلة والجنس في اتخاذ القرار فقد أظهرت النتائج وجود تفاعل ثنائي دال إحصائيا اذ بلغت القيمة الفائية المحسوبة $(15,426)$ وهي أعلى من القيمة الفائية الجدولية عند مستوى دلالة (0,05) وبدرجتي حرية (1-97) والبالغة(3,92) ولمتابعة دلالة الفروق استخدمت الباحثة اختبار شيفيه للمقارنات البعدية المتعددة والجدول(5) يوضح ذلك.

جدول (5) /ختبار شيفيه للمقارنات البعدية المتعددة

\begin{tabular}{|c|c|c|c|c|}
\hline الدلالة & قيمة شيفيه المحسوبة & الوسط الحسابي & عدد الافراد & المقارنات \\
\hline غير دلالة & 0,824 & $\begin{array}{c}97,388 \\
100,424\end{array}$ & $\begin{array}{l}18 \\
42\end{array}$ & ذكور اعدادية \\
\hline غير دالة & 2,877 & $\begin{array}{c}97,388 \\
110,666\end{array}$ & $\begin{array}{l}18 \\
15\end{array}$ & ذكور اعدادية \\
\hline غير دالة & 1,870 & $\begin{array}{l}97,388 \\
90,029\end{array}$ & $\begin{array}{l}18 \\
26\end{array}$ & ذكور اعدادية \\
\hline غير دالة & 2,602 & $\begin{array}{l}110,666 \\
100,424\end{array}$ & $\begin{array}{l}15 \\
42\end{array}$ & ذكور مـتوسطة اعدادية \\
\hline دالة & 4,944 & $\begin{array}{c}110,666 \\
90,029\end{array}$ & $\begin{array}{l}15 \\
26\end{array}$ & اناث اعدادية \\
\hline غير دالة & 3,341 & $\begin{array}{c}90,029 \\
100,424\end{array}$ & $\begin{array}{l}26 \\
42\end{array}$ & ذكور متتوسطة متوسطة \\
\hline
\end{tabular}

اظهرت نتائج المقارنة بين مجموعتي (ذكور اعدادية، ذكور متوسطة) عدم وجود فروق دالة احصائيا إذ بلغت قيمة شيفيه المحسوبة (0,824)، درجة وهي أصغر من قيمة شيفيه الحرجة البالغة (3,429). واظهرت نتائج المقارنة بين مجموعتي (ذكور اعدادية، اناث اعدادية) عدم وجود فروق دالة احصائيا إ ذ بلغت قيمة شيفيه المحسوبة (2,877)، درجة وهي أصغر من قيمة شيفيه الحرجة البالغة (3,429). واظهرت نتائج المقارنة بين مجموعتي (ذكور اعدادية، اناث متوسطة) عدم وجود فروق دالة احصائيا إذ بلغت قيمة شيفيه المحسوبة (1,870)، درجة وهي أصغر من قيمة شيفيه الحرجة البالغة (3,429). واظهرت نتائج المقارنة بين مجموعتي (اناث اعدادية، ذكور متوسطة) عدم وجود فروق دالة احصائيا إذ بلغت قيمة شيفيه الهحسوبة (2,602)، درجة وهي أصغر من قيمة شيفيه الحرجة البالغة (3,429). أما بالنسبة للمقارنة بين مجموعتي (اناث اعدادية، اناث متوسطة) وجود فروق دالة احصائي لصالح (اناث الاعدادية) إذ بلغت قيمة شيفيه المحسوبة (4,944)، درجة وهي أكبر من قيمة شيفيه الحرجة البالغة (3,429). واظهرت نتائج المقارنة بين مجموعتي (اناث متوسطة، ذكور متوسطة) عدم وجود 
فروق دالة احصائيا إذ بلغت قيمة شيفيه المحسوبة (3,429)، درجة وهي أصغر من قيمة شيفيه الحرجة البالغة (3,429).

وتعزو الباحثة سبب ذلك الى ان مديرات المدارس الاعدادية أكثر اهتمام بتفصيلات العمل الدقيق وأنهن أكثر التزاما بالقوانين وحرفية تطبيقها وأكثر التزاما بالتسلسل الهرهي في تلقي الاوامر وتنفيذها، وتعد من أهم العوامل التي تساعد في انجاز القرار الدقة الموضوعية والهنهجية العلمية في جمع المعلومات، فالمعلومات الدقيقة تمكن متخذ القرار من التخطيط للقرار وتحديد أهدافه بوضوح وواقعية، وتساعده في المفاضلة بين البدائل المتاحة واختيار الانسب منها. (عبد الهادي,

الفروق في إدارة الانفعالات تبعا لمتغير الجنس (ذكور- اناث) والمرحلة (متوسطة-إعدادية). ولتحقيق هذا الهدف استخدمت الباحثة تحليل التباين الثنائي بتفاعل والجدول (6) يوضح ذلك.

جدول (6) تحليل التباين الثنائي للكشف عن دلالة الفرق في/دارة الانفعالات بحسب متغير الجنس ذكور واناث

\begin{tabular}{|c|c|c|c|c|c|}
\hline 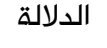 & القيمة الفائية المحسوبة & متوسط المربعات & درجة الحرية & مجموع المربعات & هصدر التباين \\
\hline 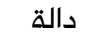 & 16,504 & 6536,809 & 1 & 6536,809 & المرحلة \\
\hline 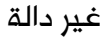 & 0,960 & 380,188 & 1 & 380,188 & الجنس الجس \\
\hline \multirow[t]{3}{*}{ 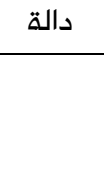 } & \multirow[t]{3}{*}{10,162} & 3983,126 & 1 & 3983,162 & المرحلة + الجنس \\
\hline & & 396,083 & 97 & 38420,030 & الخطأ (المتبقي) \\
\hline & & & 100 & 49092,693 & الكلي \\
\hline
\end{tabular}

أظهرت النتائج بالنسبة لمتغير المرحلة وجود فروق دالة احصائيا إذ بلغت القيمة الفائية المحسوبة (16,504) وهي أعلى من القيمة الفائية الجدولية عند مستوى دلالة (0,05) وبدرجتي حرية (1-97) والبالغة $(3,92)$ وبالمقارنة بين المتوسطات نجد ان الوسط الحسابي لمدراء المرحلة الاعدادية والبالغ (164,424) اعلى من الوسط الحسابي لمدراء المرحلة المتوسطة والبالغ $(149,573)$ مما يشير الى ان مدراء المدارس الاعدادية هم أكثر قدرة على ادارة الانفعالات. اما بالنسبة لمتغير الجنس فقد اظهرت النتائج عدم وجود فروق دالة احصائيا اذ بلغت القيمة الفائية المحسوبة (0,960) وهي أصغر من القيمة الفائية الجدولية عند مستوى دلالة (0,05) وبدرجتي حرية (1-97) والبالغة (3,92). اما بالنسبة للتفاعلات النهائية بين الهرحلة والجنس في ادارة الانفعالات فقد اظهرت النتائج وجود تفاعل ثنائي دال احصائيا اذ بلغت القيمة الفائية المحسوبة (10,56) وهي أعلى من القيمة الفائية الجدولية عند مستوى دلالة (0,05) وبدرجتي حرية (1-197) والبالغة (3,92) ولمتابعة دلالة الفروق استخدمت الباحثة اختبار شيفيه للمقارنات للمقارنات البعدية المتعددة والجدول (7) يوضح ذلك. 

Volume: 2, No:3

\begin{tabular}{|c|c|c|c|c|}
\hline \multicolumn{5}{|c|}{ جدول (7) /ختبار شيفيه للمقارنات البعدية المتعددة } \\
\hline الدلالة & قيمة شيفيه المحسوبة & الوسط الحسابي & عدد الافراد & المقارنات \\
\hline غير دالة & 0,723 & $\begin{array}{l}160,166 \\
156,357\end{array}$ & $\begin{array}{l}18 \\
42\end{array}$ & ذكور اعدادية \\
\hline غير دالة & 1,419 & $\begin{array}{l}160,166 \\
169,533\end{array}$ & $\begin{array}{l}18 \\
15\end{array}$ & ذكور اعدادية \\
\hline 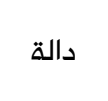 & 3,828 & $\begin{array}{l}160,166 \\
138,615\end{array}$ & $\begin{array}{l}18 \\
26\end{array}$ & ذكاث متور اعدادية \\
\hline غير دالة & 2,340 & $\begin{array}{l}169,533 \\
156.357\end{array}$ & $\begin{array}{l}15 \\
42\end{array}$ & ذكور متوسطة اعدادية \\
\hline 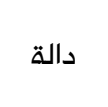 & 5,178 & $\begin{array}{l}169,533 \\
138,615\end{array}$ & $\begin{array}{l}15 \\
26\end{array}$ & اناث متوسطة اعدادية \\
\hline 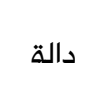 & 3,986 & $\begin{array}{l}138,615 \\
156,357\end{array}$ & $\begin{array}{l}26 \\
42\end{array}$ & ذكور متوسطة متوسطة \\
\hline
\end{tabular}

اظهرت نتائج المقارنة بين مجموعتي (ذكور اعدادية، ذكور متوسطة) عدم وجود فروق دالة احصائيا إذ بلغت قيمة شيفيه المحسوبة (0,723)، درجة وهي أصغر من قيمة شيفيه الحرجة البالغة (3,429). واظهرت نتائج المقارنة بين مجموعتي (ذكور اعدادية، اناث اعدادية) عدم وجود فروق دالة احصائيا إذ بلغت قيمة شيفيه الهحسوبة (1,419)، درجة وهي أصغر من قيمة شيفيه الحرجة البالغة (3,429). واظهرت نتائج المقارنة بين مجموعتي (ذكور اعدادية، اناث متوسطة) وجود فروق دالة احصائيا لصالح (ذكور اعدادية) إذ بلغت قيمة شيفيه المحسوبة (3,828)، درجة وهي أصغر من قيمة شيفيه الحرجة البالغة (3,429). واظهرت نتائج المقارنة بين مجموعتي (اناث اعدادية، ذكور متوسطة) عدم وجود فروق دالة احصائيا إذ بلغت قيمة شيفيه المحسوبة (2,340)، درجة وهي أصغر من قيمة شيفيه الحرجة البالغة (3,429). أما بالنسبة للمقارنة بين مجموعتي (اناث اعدادية، اناث متوسطة) وجود فروق دالة احصائيا لصالح (اناث الاعدادية) إذ بلغت قيمة شيفيه المحسوبة (5,178)، درجة وهي أكبر من قيمة شيفيه الحرجة البالغة (3,429). واظهرت نتائج المقارنة بين مجموعتي (اناث متوسطة، ذكور متوسطة) وجود فروق دالة احصائيا لصالح (ذكور متوسطة) إذ بلغت قيمة شيفيه المحسوبة (3,986)، درجة وهي أصغر من قيمة شيفيه الحرجة البالغة (3,429).

وهذا يشير الى ان القدرة على ادارة الانفعالات تتأثر بمتغير الجنس(ذكور - أناث), فالذكور ذوي ادارة الانفعالات المرتفعة يتصفون بالتوازن الاجتماعي وتحمل المسؤولية حيث ان مديري المدارس الذين يتمتعون بإدارة انفعالات عالية يتميزون باستخدام المعرفة للحفاظ على الهدوء, والتحكم في 
الانفعالات والتفاؤل وحل المشكلات وفهم انفعالات الاخرين لمنع تصعيد الهنازعات وبناء روابط الثقة مع الاخرين (Geery,1997:251)، في حين ان الاناث يعجزون عن التحكم في مشاعرهم ويشعرون بالإحباط سريعاً, وغير قادرين على التكيف، ولا يميلون الى التحدث والتجديد. (حبيب,2009: 31). أما بالنسبة للمقارنة بين مجموعتي (اناث اعدادية، اناث متوسطة) وجود فروق دالة احصائيا لصالح (اناث الاعدادية) وهذا يشير الى ان الاناث ذوات ادارة الانفعالات المرتفعة يتسمن بالتعبير عن مشاعرهن بصورة مباشرة، ويثقن في قدراتهن, بالإضافة الى انهن مثل الرجال اجتماعيات غير متحفظات، كما انهن يستطعن التكيف مع الضغوط النفسية، ومن السهل عليهن تكوين علاقات اجتماعية جيدة ولديهن القدرة على أحداث نوعاً من التوازن بين الانفعال والعقل عند أتخاذ القرارات (الجبالي,71:2000). التعرف على العلاقة بين اتخاذ القرار وادارة الانفعالات لدى هدراء المدارس المتوسطة والاعدادية لمعرفة علاقة اتخاذ القرار بإدارة الانفعالات لدى مدراء المدارس المتوسطة والاعدادية تم حساب معامل الارتباط بين درجات أفراد العينة على مقياس اتخاذ القرار ودرجاتهم على مقياس ادارة الانفعالات تم التحقق من العلاقة بين المقياسين باستخدام معامل ارتباط (بيرسون) اظهرت النتائج بالنسبة للعلاقة بين اتخاذ القرار ادارة الانفعالات وجود علاقة موجبة دالة احصائياً اذ بلغت قيمة معامل الارتباط المحسوبة (872,) وهي اعلى من قيمة معامل الارتباط الجدولية (196, 0) عند مستوى دلالة (01, 0).

$$
\text { والجدول (8) يوضح ذلك. }
$$

الجدول (8) العلاقة بين/تخاذ القرار وادارة الانفعالات لدى مدراء المدارس المتوسطة والاعد/دية

\begin{tabular}{|c|c|c|c|c|}
\hline \multirow{2}{*}{ مستوى الدلالة } & \multirow{2}{*}{ درجة الحرية } & \multicolumn{2}{|c|}{ قيمة معامل ارتباط بيرسون } & \multirow{2}{*}{ العلاقة ككل } \\
\hline & & الجدولية & المحسوبة & \\
\hline 0,01 & & 0,196 & 872, & ادارة الانفاذ القرار \\
\hline
\end{tabular}

وترى الباحثة ان هذه العلاقة جاءت من ان المدير الذي تكون له القدرة على ادارة انفعالاته يمتلك القدرة على اتخاذ القرارات الجيدة، وهي نتيجة طبيعية حيث يتصف المدراء بقدرتهم على اتخاذ القرار وذلك بحكم وظيفتهم ومكانتهم، كون اتخاذ القرار وظيفة أساسية وههمة من وظائف الإدارة، لان نجاح أي عملية إدارية يرتبط بصنع واتخاذ القرارات فضلا عن كونها المحرك الأساسي والفعال لجهود العاملين في المنظمة بغية تحقيق أهدافها المحددة. (الخشروم وهرسي، 1998: 273)، والمدير الذي لديه القدرة على ادارة انفعالاته يتمكن من الاحتفاظ بالمرونة اللازمة لإدارة مختلف المواقف الصعبة وهذا يتفق مع دراسة (ماكالبو2009) لتي اشارت الى ان الاتزان الانفعالي عامل مهم ومساعد في انجاح الدور القيادي وتمكنه بالتالي من التوصل الى خيارات سلوكية سليمة. 
1) ان المدراء في المدارس المتوسطة والاعدادية لديهم القدرة على اتخاذ القرارات المهمة والصعبة في المواقف المختلفة وهذه يرجع الى السمات الشخصية التي يتمتعون بها فضلا عن الخبرة المراكمة جعلتهم أكثر نضجا في الجانب الاداري واتخاذ القرارات الهناسبة

2) ان ادارة الهدير والهديرة لذاتها وكذلك قدرتهم على ادارة الاخرين جعلهم أكثر ثقة بأنفسهم في اتخاذ القرار الصائب والتعامل الجيد مع المواقف ومع الاخرين من الهدرسين والطلبة فضلا عن الضغوط المجتمعية التي جعلتهم يواجهون المواقف الصعبة بإيجابية. 3) أن المدراء لديهمم مستوى عالي من القدرة على اتخاذ القرار يعود هذا الى ثقتهم بأنفسهم وقدرتهم على حل المشكلات التربوية والتعليمية في المدارس والتعامل الايجابي مع جميع الظروف والمواقف

$$
\text { التي تتطلب الادارة والحسم. }
$$

4) ان المدراء في المدارس المتوسطة والاعدادية لديهم إدراك عالي ووعي ذاتي مرتفع في ضبط ذواتهم وبيئتهم جعلهم أكثر قدرة على ادارة انفعالاتهم والسيطرة على عواطفهم في المواقف الحرجة والصعبة نتيجة للتعامل مع الواقع اليوهي الصعب والظروف المتقبلة في المجتمع فكانوا اكثر مهارة في ادارة اوقاتهم ومشاعرهم وانفسهم فضلا عن عكس مشاعرهم تجاه الاخرين، والابتعاد عن الغض في المواقف الشديدة. 5) ان قدرة المدير والمديرة على ادارت ذواتهم جعلهم أكثر قدرة على اتخاذ القرارات الناجحة في اغلب المواقف التعليمية والتربوية، وان الظروف المتشابه التي يمر بها افراد المجتمع جعل الذكور والاناث في يواجهون هذه الظروف بوعي ذاتي عالي لذلك كانت هناك علاقة ايجابية بين متغيرات البحث.

\section{5. التوصيات}

1) اقامة دورات تدريبية لمدراء الهدارس في اتخاذ القرار يتعلمون كيفية اتخاذ القرارات وما هي الخطوات التي من المهم إتباعها للوصول الى قرارات صائبة وتدريبهم على الههارات القيادية والادارية، وتشجيعهم بتكريم المدراء القياديين الذين لهم القدرة على اتخاذ القرار. 2) تدريب المدراء على كيفية ادارة الوقت وادارة الاداء بالتزامن مع التدريب على ادارة المشاعر والعواطف حتى يكونوا أكثر على الانجاز الههني.

Jawad, N. (2019). Decision making Relation to Emotions management at Headmasters of Secondary and Preparatory Schools. Journal Port Science Research, 2(3), 567-592. doi.org/10.36371/port.2018.02.3.12. 


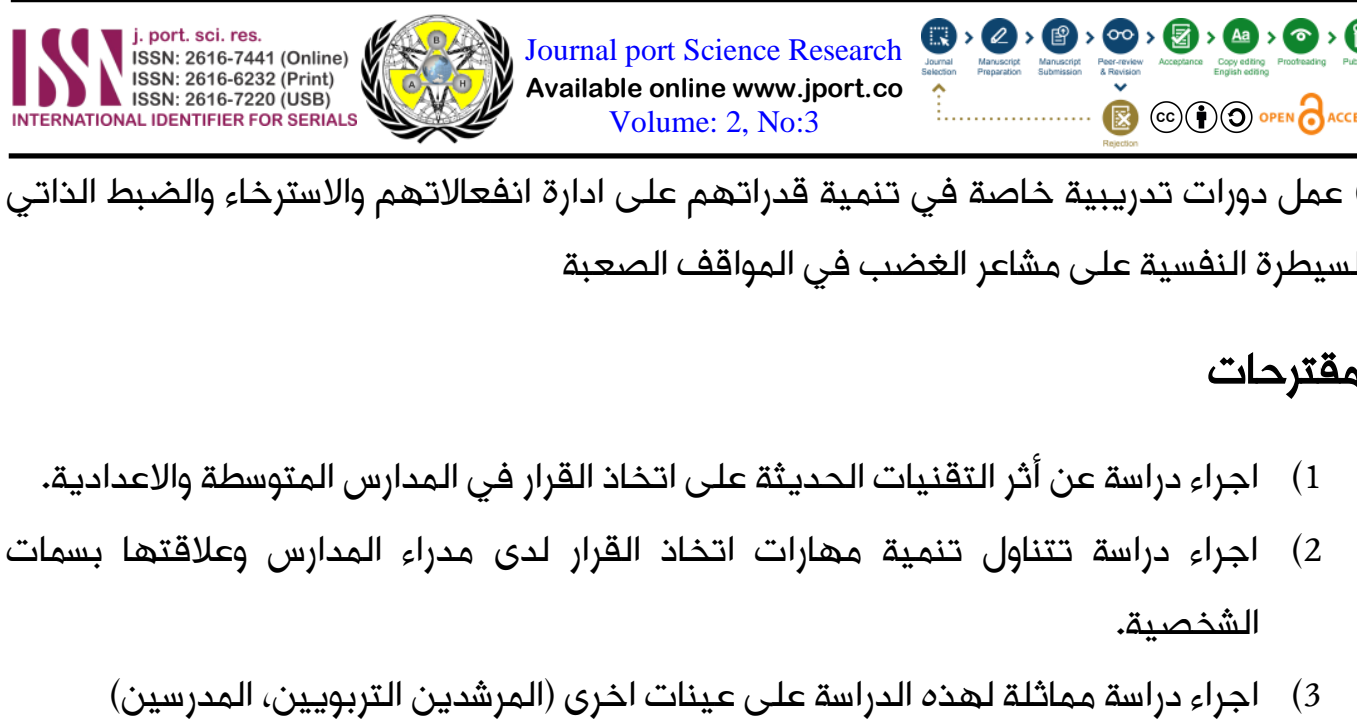

\section{References}

[1] Abbas Ali. (2012). تأثير أنماط القيادة الإدارية على عملية صنع قرارات التغيير (دراسة تطبيقية في شركة الكهرياء (الوطنية الأردنية). Journal of the Islamic University for Economic and Administrative Studies. 1(20). https: / / journals.iugaza.edu.ps / index.php/IUGJEB/article/view / 424

[2] Yaghi, Mohamed Abdel Fattah. (2002). اتخاذ القرارات التنظيمية> . Amman: Dar Al Awael for Printing, Publishing and Distribution. https://www.neelwafurat.com/itempage.aspx?id=lbb194255163943\&search=books

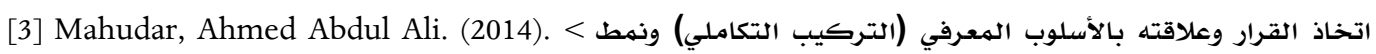

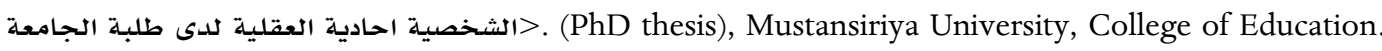
http:/ / www.iraqnla-iq.com/opac2/ fullrecr.php?nid=30101\&hl=ara

[4] Blickle, G., Momm, T. S., Kramer, J., Mierke, J., Liu, Y., \& Ferris, G. R. (2009). Construct and criterion-related validation of a measure of emotional reasoning skills: A two-study investigation. International Journal of Selection and Assessment, 17(1), 101-118. https:// doi.org/10.1111/j.1468-2389.2009.00455.x

[5] Alghamdi, Ali bin Mohammed. (2015). واقع عملية اتخاذ القرار الإداري لدى مديري مدارس التعليم العام

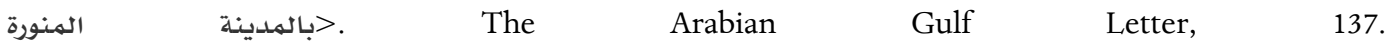
https://storage.googleapis.com/abegsjournal/researchs/137/13704.pdf

[6] Canaan, Nawaf. (2011) > اتخاذ القرارات الادارية بين النظرية والتطبيق . Dar Al Thaqafa for Publishing \& Distribution. https://jarir.com/arabic-books-369497.html

[7] Darwish, Ismail bin Mohammed. (2012) معوقات اتخاذ القرار في الادارة المدرسية في التعليم العام في مدينة > Mohammed bin Saud Islamic University.

[8] Shaaban, Kamel Al-Farrakh and Tim, Abdul Jaber. (1999). النمو الانفعالي عند الطفل> >. Sana'a Publishing and Distribution House, Amman.

جواد، نورا حازم. (2019). اتخاذ القرار وعلاقته بإدارة الانفعالات لدى مدراء المدارس المتوسطة والاعدادية. Journal Port doi.org/10.36371/port.2018.02.3.12.567-592 ، (3)2 ، Science Research 
[9] Al-Lami, Ahmad Fadhel Abbas. (2014). علاقة إدارة الانفعالات بالأنماط القيادية لدى مديري ومديرات المدارس الإعدادية . College of Education, Mustansiriya University.

[10] Jervis, R. L., Janis, I., \& Mann, L. (1978). Decision Making: A Psychological Analysis of Conflict, Choice, and Commitment. Political Science Quarterly, 93(1), 134. https:// doi.org/10.2307/2149070

[11] Mayer, J. D., Salovey, P., Caruso, D. R., \& Sitarenios, G. (2001). Emotional Intelligence as a Standard Intelligence. Emotion, 1(3), 232-242. https:// doi.org/10.1037/1528-3542.1.3.232

القدرة على اتخاذ القرار وعلاقته بكل من فاعلية الذات والمساندة > . 112] Mosbeh, Mostafa Attia Ibrahim. (2011

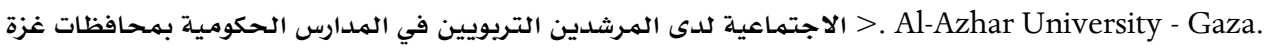

[13] Abdul Hadi, Fakhri. (2010). ملم النفس المعرفي> Ossama Publishing House. https: / / www.neelwafurat.com/itempage.aspx?id=lbb192927-162531\&search=books

[14] Alkhchrom, Mohammed bin Mustafa. Morsi, Nabil Mohamed. (1998). ادارة الاعمال المباديء والمهارات و . Dar Al-Shaqri Publishing \& Distribution, Riyadh, Saudi Arabia. https://www.jarir.com/arabic-books-140487.html

[15] Al-Badri, Tariq Abdul Hamid. (2002). اساسيات في علم ادارة القيادة> > Dar Al Fikr Publishers and Distributors. https:/ / www.daralfiker.com/node/6911

[16] Monthly, Saad Mohammed Ali. (2009). الذكاء الوجداني وعلاقته باتخاذ القرار لدى عينة من موظفي القطاع (C) (العام والقطاع الخاص بمحافظة الطائف > (Master Thesis) Umm Al-Qura University, College of Education, Saudi Arabia. http:/ / thesis.mandumah.com/Record/192149

[17] Mann, L., Burnett, P., Radford, M., \& Ford, S. (1997). The Melbourne decision making questionnaire: An instrument for measuring patterns for coping with decisional conflict. Journal of Behavioral Decision Making, 10(1), 1-19. https://doi.org/10.1002/(SICI)10990771(199703)10:1<1::AID-BDM242>3.0.CO;2-X

[18] Nuaimi, Muhannad Mohammed Abdul Sattar. (1995). الاسلوب المعرفي التأملي الاندفاعي و علاقته > بالقدرة على اتخاذ القرار لدى موظفي الدولة iq.com/opac2 / fullrecr.php?nid=12245\&hl=ara

[19] Rosete, D., \& Ciarrochi, J. (2005). Emotional intelligence and its relationship to workplace performance outcomes of leadership effectiveness. Leadership and Organization Development Journal, 26(5), 388-399. https:/ / doi.org/10.1108/01437730510607871

[20] Goleman, D. D. (1995). Emotional intelligence: Why it can matter more than IQ for character, health and lifelong achievement. Bantam Books, 1995 (p. 352). https://doi.org/10.1016/S0962$\underline{1849(05) 80058-7}$

[21] Hakami, Ibrahim Hassan. (2004). اثر التخصص الدراسي ووجهة الضبط على الذكاء الشخصي لطلاب جامعة . Journal of Umm Al-Qura University, 16(1).

[22] Multiple intelligences: the theory in practice. (1993). Choice Reviews Online, 31(02), 31-1214-311214. https: / / doi.org/10.5860/ choice.31-1214

587 [23] Goleman, D. (1996). Emotional Intelligence. Why It Can Matter More than IQ. Learning, 24(6), 49-50.

Jawad, N. (2019). Decision making Relation to Emotions management at Headmasters of Secondary and Preparatory Schools. Journal Port Science Research, 2(3), 567-592. doi.org/10.36371/port.2018.02.3.12. 
[24] Hussein, Ghada Faisal. (2016). Managing emotions and its relationship with some variables among teachers and sports education teachers and other materials at the secondary School. Journal: Karbala Magazine of Physical Edu. Seiences. 2(4). https: / / www.iasj.net/iasj?func=fulltext\&aId=129061

[25] Salovey, P., \& Mayer, J. D. (1990). Emotional Intelligence and Its Relationship to Other Intelligences. Imagination, Cognition and Personality, 9(3), 185-211. https://doi.org/10.1037/0022$\underline{3514.50 .2 .421}$

[26] Cherniss, C., Roche, C., \& Barbarasch, B. (2015). Emotional Intelligence. In Encyclopedia of Mental Health: Second Edition (pp. 108-115). Elsevier Inc. https: / / doi.org/10.1016/ B978-0-12-397045-9.00207$\underline{\mathrm{X}}$

[27] Howe, D., \& Howe, D. (2008). What is Emotional Intelligence? In the Emotionally Intelligent Social Worker (pp. 10-23). Macmillan Education UK. https:/ / doi.org/10.1007/978-0-230-36521-6_2

[28] Al-Aity, Yasser. (2006). لذكاء العاطفي - نظرة جديدة في العلاقة بين الذكاء والعاطفة > Publisher: Dar Al Fikr Publishing and Distribution. https:// www.noor-book.com/book/review/15218

[29] Mamaria, Bashir. (2009). دراسات نفسية حول طلاب المدارس والجامعات وفئات أخرى > Cairo: Modern

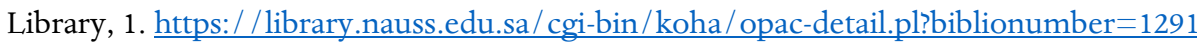

[30] Yang, F. M., \& Kao, S. T. (2014). Item response theory for measurement validity. Shanghai Archives of Psychiatry, 26(3), 171-177. https:// doi.org/10.3969/j.issn.1002-0829.2014.03

[31] Reeve, B. (2002). An introduction to modern measurement theory. National Cancer Institute, USA, (301). Retrieved from http:/ / faculty.ksu.edu.sa/darandari/spss/IRT.pdf

[32] de C. Marshall, T. F., \& Fleiss, J. L. (1976). Statistical Methods for Rates and Proportions. The Statistician, 25(1), 70. https: / / doi.org/10.2307/2988144

[33] Stockton, R., \& Kerlinger, F. N. (1974). Foundations of Behavioral Research. American Educational Research Journal, 11(3), 292. https: / / doi.org/10.2307/1162206

[34] Imam, Mustafa Mahmoud and others. (1995). التقويم والقياس> > House of Wisdom for Printing and Publishing, Baghdad.

[35] Perkins, D., \& Bishopp, D. (2017). Psychological testing. In Forensic Psychiatry: Fundamentals and Clinical Practice (pp. 559-565). Taylor and Francis. https:// doi.org/10.1201/9781315380797

الملاحق ملحق رقم (1)

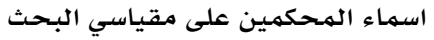

\begin{tabular}{|c|c|c|c|}
\hline 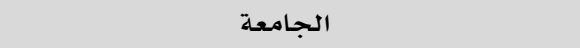 & 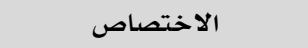 & أسماء الخبراء والقابهم العلمية & ت \\
\hline الجامعة المستنصرية/ كلية التربية الاساسية & علم النفس التريوي & أ.د حيدر كريم سكر & 1 \\
\hline وزارة التربية/معهد الفنون الجميلة & قياس تقويم & أ.م. د امل ابراهيهم عبد الخالق & 2 \\
\hline وزارة التربية/ المديرية العامة لتربية بغداد الكرج/3 & ارشاد نفسي وتوجيه تربوي & أ.م. د حسن أحمد القره غولي & 3 \\
\hline الجامعة المستنصرية/ كلية التربية & علم النفس التربوي & أ.م. د سحر هاشم محمد & 4 \\
\hline الجامعة المستنصرية/ كلية التربية & علم النفس التربوي & أ.م. د سهيلة عبد الرضا & 5 \\
\hline الجامعة المستتصرية/ كلية التربية & علم النفس التربوي & أ.م. د لمياء ياسين & 6 \\
\hline الجامعة المستنصرية/ كلية التربية & علم النفس التربوي & أ.م. د بشرى كاظم الشمري & 7 \\
\hline
\end{tabular}

جواد، نورا حازم. (2019). اتخاذ القرار وعلاقته بإدارة الانفعالات لدى مدراء المدارس المتوسطة والاعدادية. Journal Port doi.org/10.36371/port.2018.02.3.12.567-592 ، S(3) ، Science Research 

Volume: 2, No:3

\begin{tabular}{|c|c|c|c|}
\hline الجامعة المستنصرية/ كلية التربية & عله النفس التريوي & أ.م. د رحيه عبد الله & 8 \\
\hline الجامعة المستنصرية/ كلية التربية & علهم النفس الاجتمـاعي & أ.م. د عبد الكريهم جعو & 9 \\
\hline
\end{tabular}

\section{ملحق رقم (2)}

مقياس اتخاذ القرار بصيغته النهائية

$$
\begin{aligned}
& \text { عزيزي المدير......................................................... }
\end{aligned}
$$

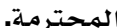

$$
\begin{aligned}
& \text { عزيزتي المديرة... } \\
& \text { تحية طيبة.. }
\end{aligned}
$$

نضع بين يديك عدداً من الفقرات التي تتناول مواقف مختلفة في الحياة، يرجى منك وضع علامة ( ل ل تحت البديل الذي ينطبق عليك من بين البدائل الخمسة، وكما هو مبين في المثال أدناه، مـع العلم أنه ليس هناك إجابة صحيحة أو خاطئة

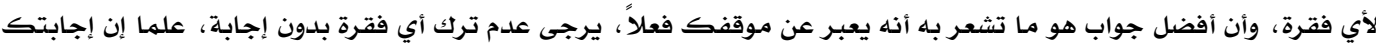

\begin{tabular}{|c|c|c|c|c|c|}
\hline علا لاّ تنطبقً & عليّ بلدرجة قليقة & تبطبق عليّ & تنطبق عليّ & بدربة كبيق عليّة & الفقرة \\
\hline & & $\sqrt{ }$ & & & أشُعْرُ بـالثقة بمقدرتي على اتخاذ القرارات. \\
\hline
\end{tabular}
تستخدم لأغراض البحث العلهي ولن يطلع عليها أحد سوى الباحثة، لذا لا داعي لذكر الاستهم.

ملاحظة:

قبل أن تبدأ بالإجابة يرجى تدوين المعلومات التالية: أنثى:

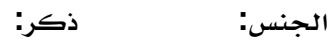
مـع جزيل الشكر ووافر الامتتنان

\begin{tabular}{|c|c|c|c|c|c|c|}
\hline لا لا تنطبق عليّ & بندرجة قليلة & بندرجة معتدلة & بدرجة كبيرة عليّ & |تنطبق عليّ بدرجة & الفقرات & ت \\
\hline & & & & & أَثْعُرُ بالثقة بمقدرتي على اتخاذ & 1 \\
\hline & & & & & عندما اتخذ القرار، أثق بمشاعري & 2 \\
\hline & & & & & عندما اتخذ القرارات، اعتمد على موهبتي & 3 \\
\hline & & & & & اعتقد أني متخذذ قرار جيد & 4 \\
\hline & & & & & أحب أن اتخذ قراراتي بنفسي & 5 \\
\hline & & & & & من السهل على الآخرين أن يقنعوني & 6 \\
\hline & & & & & عندما اتخذ قرارا ما فأنني اختار & 7 \\
\hline & & & & & اتخذ القرارات بطريقة منطقية & 8 \\
\hline & & & & & اتخاذي للقرار يتطلب مني تفكيرا & 9 \\
\hline & & & & & 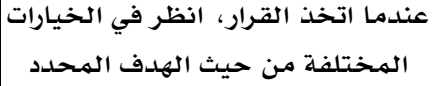 & 10 \\
\hline
\end{tabular}

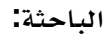

Jawad, N. (2019). Decision making Relation to Emotions management at Headmasters of Secondary and Preparatory Schools. Journal Port Science Research, 2(3), 567-592. doi.org/10.36371/port.2018.02.3.12. 


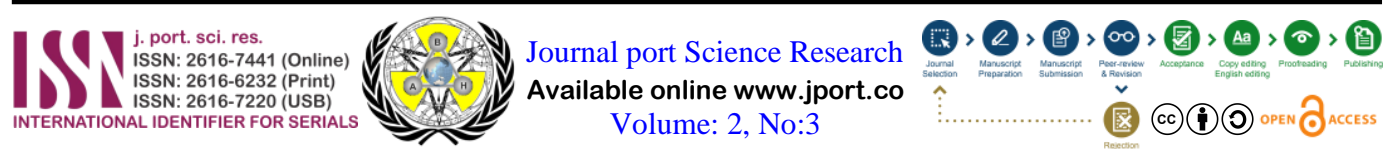

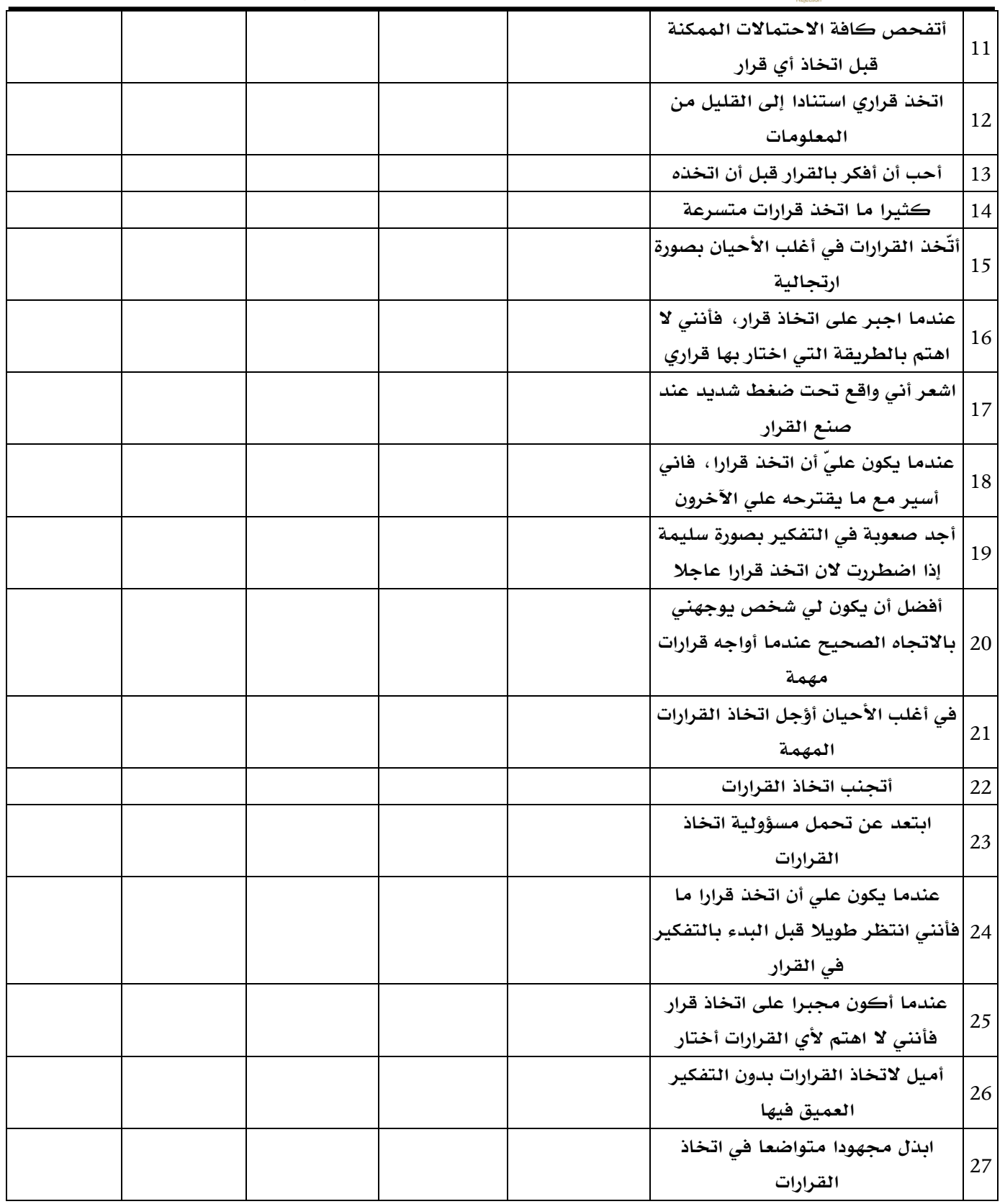

\section{ملحق (3)}

مقياس ادارة الانفعالات بصورته النهائية 


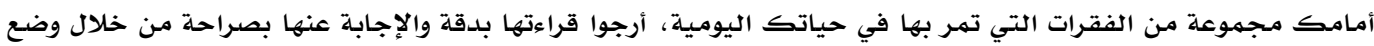

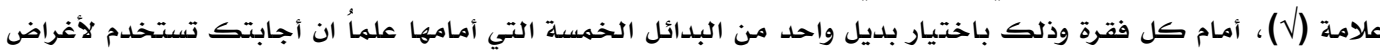
البحث العلمي فقط ولن يطلع عليها سوى الباحثة. باحئ.

\begin{tabular}{|c|c|c|c|c|c|c|}
\hline لا تنطبق على أبداً & تنطبق على & $\begin{array}{l}\text { تنطبق على } \\
\text { أحياناً }\end{array}$ & غنطبق على & تنطبق على & الفقرات & ت \\
\hline & & $\sqrt{ }$ & & & أحاول تعديل شعوري بالغضب & 1 \\
\hline
\end{tabular}

مع جزيل الشكر والتقدير لتعاونكم

الجنس: ذكر $\quad$ أنثى

الباحثة

\begin{tabular}{|c|c|c|c|c|c|c|}
\hline أبداً & نادراً & أحياناً & 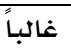 & دائماً & الفقرات & ت \\
\hline & & & & & أحب مشاركة الاخرين مناسباتهم في حالة الفرح والحزن. & 1 \\
\hline & & & & & مشاعري نحو الاخرين واضحة بالنسبة لهم. & 2 \\
\hline & & & & & أشعر بالتفاؤل حتى في أصعب المواقف. & 3 \\
\hline & & & & & افرح مـع الاخرين رغم شعوري بالحزن. & 4 \\
\hline & & & & & اتحاشى الأشخاص الغيورين. الغخاص. & 5 \\
\hline & & & & & أحب مشاركة الاخرين الحديث والتواصل معهم. & 6 \\
\hline & & & & & أفضل ان اكون مـع مجموعة من الاشخاص على ان اكون لوحدي. & 7 \\
\hline & & & & & تربطني علاقة وطيدة بزملائي في العمل. & 8 \\
\hline & & & & & اهتم برغبات وحاجات الاخرين بقدر الاهتمام برغباتي وحاجاتي. & 9 \\
\hline & & & & & أتدخل لحل النزاعات بين الاخرين بشكل ايجابي. & 10 \\
\hline & & & & & أظهر مشاعري للأخرين اثناء تعاملي معهم. & 11 \\
\hline & & & & & عندما احتاخ الى مساعدة اطلبها من الآخرين دون تردد. & 12 \\
\hline & & & & & أقدم النصائح للأخرين بشكل منفرد. & 13 \\
\hline & & & & & أخفي مشاعري عن الأخرين أذا كان اظهارها غير مناسب في ذلك الوقت. & 14 \\
\hline & & & & & لدي القدرة على التغلب على احزاني بأسرع وقت. & 15 \\
\hline & & & & & أتمكن من كبت مشاعر الغضب مهما كانت شديدة. & 16 \\
\hline & & & & & أخفي مشاعري السلبية تجاه الاخرين عندما اتعامل معهم. & 17 \\
\hline & & & & & أستطيع ان أتواصل مـع الاخرين عندما يتحدثون بسرعه امامي. & 18 \\
\hline & & & & & أومن بالقول (العفو عند المقدرة) واعمل به. & 19 \\
\hline & & & & & افهم مشاعر الأخرين من تعابير وجوههم. & 20 \\
\hline & & & & & اظهر الحب والاحترام لكل من انجز عمله. & 21 \\
\hline & & & & & يصعب علي إخفاء مشاعري تجاه شخص غير محبوب لدي. & 22 \\
\hline & & & & & اتقبل نقد الاخرين لي بكل رحابة صدر. & 23 \\
\hline & & & & & اوظف خبرتي ومهارتي في العمل دون غرور. & 24 \\
\hline & & & & & أتفهم انتقادات الأخرين لي وأحاول الاستفادة منها. & 25 \\
\hline & & & & & لدي القدرة على امتصاص انفعال الغضب لدى الاخرين. & 26 \\
\hline & & & & & أفكر ملياً في مـا أريد قوله قبل التفوه به. & 27 \\
\hline & & & & & أشعر بالندم عندما أرتكب خطاً بحق شخصاً ما. & 28 \\
\hline
\end{tabular}

Jawad, N. (2019). Decision making Relation to Emotions management at Headmasters of Secondary and Preparatory Schools. Journal Port Science Research, 2(3), 567-592. doi.org/10.36371/port.2018.02.3.12. 
j. port. sci. res.

ISSN: 2616-7441 (Online)

ISSN: 2616-6232 (Print) INTERNATIONAL IDENTIFIER FOR SERIALS

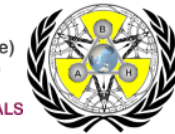

Journal port Science Research

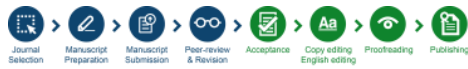
Available online www.jport.co Volume: 2, No:3

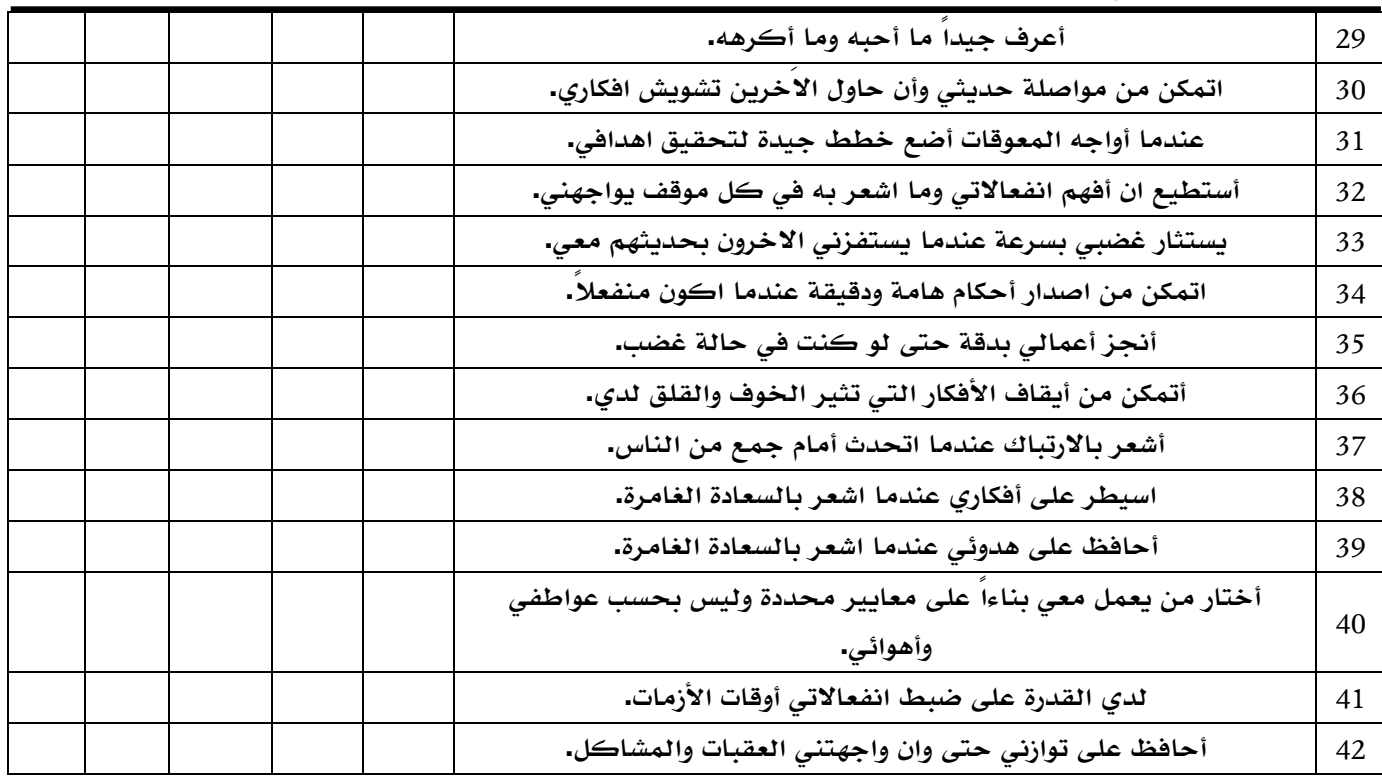

